\title{
Function of the Cold Receptor (TRPM8) Associated with Voiding Dysfunction in Bladder Outlet Obstruction in Rats
}

\author{
Ji Hee Jun ${ }^{1,2}$, Hyo Jin Kang ${ }^{1,2}$, Mei Hua Jin ${ }^{1,2}$, Hye Young Lee ${ }^{1}$, Young Jae Im $^{1}$, Hyun Jin Jung', Sang Won Han ${ }^{1,2}$ \\ ${ }^{1}$ Department of Urology and the Urological Science Institute, ${ }^{2}$ Brain Korea 21 Project for Medical Science, Yonsei University College of Medicine, Seoul, Korea
}

Purpose: Bladder outlet obstruction (BOO) causes storage and voiding dysfunction in the lower urinary tract. We investigated the expression of transient receptor potential cation channel subfamily M member 8 (TRPM8) to evaluate the relationship between TRPM8 expression and overactive bladder $(\mathrm{OAB})$ in a rat model of $\mathrm{BOO}$.

Methods: Fifty female Sprague-Dawley rats were divided into 4 groups; normal $(\mathrm{n}=10)$, normal-menthol $(\mathrm{n}=10), \mathrm{BOO}$ $(\mathrm{n}=15)$, BOO-menthol $(\mathrm{n}=15)$. After 3 weeks, cystometry was performed by infusing physiological saline and menthol $(3 \mathrm{mM})$ into the bladder at a slow infusion rate. The histological changes and expression of TRPM8 in the bladder were investigated by Masson's trichrome staining, immunofluorescence and reverse transcription-polymerase chain reaction.

Results: Cystometry showed that the intercontraction interval (ICI; $428.2 \pm 23.4$ vs. $880.4 \pm 51.2, \mathrm{P}<0.001$ ), micturition pressure (MP; $25.7 \pm 1.01$ vs. $71.80 \pm 3.01, \mathrm{P}<0.001)$, and threshold pressure $(2.9 \pm 0.25$ vs. $9.2 \pm 1.58, \mathrm{P}<0.01)$ were significantly increased in $\mathrm{BOO}$ rats. The bladder wall was significantly dilated compared with the control. Detrusor muscle hypertrophy and a thick mucosa layer were observed in BOO bladder. After menthol treatment, ICIs were decreased and MPs were increased in the menthol treatment groups. TRPM8-positive cells and mRNA were predominantly increased in the bladder and dorsal root ganglia of all groups compared with the normal group.

Conclusions: Increased bladder wall thickness and proportion of collagen probably affect voiding dysfunction. Furthermore, an increase of TRPM8 expression in BOO may induce entry of $\mathrm{Ca}^{2+}$ from the extracellular space or stores. The increase of $\mathrm{Ca}^{2+}$ probably causes contraction of smooth muscle in BOO. However, $\mathrm{OAB}$ symptoms were not observed after menthol treatment although the expression of TRPM8 was abundant in the bladder epithelium after menthol treatment. Although OAB in BOO models may be caused by complex pathways, regulation of TRPM8 presents possibilities for OAB treatment.

Keywords: TRPM8; Menthol; Cold receptor; Bladder outlet obstruction

\section{INTRODUCTION}

Bladder outlet obstruction (BOO) causes storage and voiding dysfunction of the lower urinary tract through various structural and functional changes including muscular hypertrophy via bladder detrusor overactivity (DO) [1,2]. These functional changes are observed in the neuronal pathway and in the micturition reflex [3]. Urgency, frequency, and urge incontinence are common BOO symptoms. Prior investigations have demonstrated increased bladder pressure on cystometry and detrusor changes leading to DO in BOO [4-6]. Diverse animal models of BOO have been used frequently to investigate the mechanism and therapeutic aspects of BOO. Cystometry studies in BOO have explained the functional changes and overactive bladder $(\mathrm{OAB})$ syndrome by an increase in bladder afferent activity $[2,7,8]$. Yuan et al. [9] demonstrated pathological remodeling and bladder dysfunction in $\mathrm{BOO}$ and the role of nitric oxide synthase (NOS) and suggested that a decrease in NOS represents the underlying pathogenic mechanism. Andersson et al. [10] reported the role of transient receptor potential cation channel subfamily
Corresponding author: Sang Won Han

Department of Urology, Yonsei University College of Medicine, 50 Yonsei-ro, Seodaemun-gu, Seoul 120-749, Korea

Tel: +82-2-2228-2316 / Fax: +82-2-312-2538 / E-mail: swhan@yuhs.ac

Submitted: April 26, 2012 / Accepted after revision: May 23, 2012
This is an Open Access article distributed under the terms of the Creative Commons Attribution Non-Commercial License (http://creativecommons.org/licenses/by-nc/3.0/) which permits unrestricted non-commercial use, distribution, and reproduction in any medium, provided the original work is properly cited. 
M member 8 (TRPM8) in OAB and suggested that increased TRPM8 channels may provide a new therapeutic opportunity for DO/OAB. TRP channels are known as cation-selective channels and multifunctional sensors at the cellular level $[11,12]$. Stein et al. [13] demonstrated the presence of TRPM8 in bladder and dorsal root ganglia (DRG) through immunofluorescence and reverse transcription-polymerase chain reaction (RT-PCR) [14,15]. TRPM8 mRNA is expressed in DRG neurons and in the epithelium of human bladder but not in the detrusor $[7,16]$. In addition to neuronal expression, this channel has also been shown on non-neuronal cells including epithelial cells [17] and synoviocytes [18] where their activation has been proposed to coordinate neural responses.

It is a cold- and menthol-sensing $\mathrm{Ca}^{2+}$ permeable channel that plays a crucial role in thermosensation and that is activated by moderate cooling $\left(<25^{\circ} \mathrm{C}\right)[7,10,12,19,20]$. TRPM8 is divided into two groups as a cold temperature- and menthol-sensitive cation channel $[21,22]$. Activation by cold or agonists (menthol, icilin) induces a transient rise in the intracellular free calcium concentration [23].

Despite substantial research efforts, however the mechanism of TRPM8 action remains controversial. In this study, therefore, we investigated the different expression of TRPM8 expression to evaluate the relationship between TRPM8 and OAB in a rat BOO models.

\section{MATERIALS AND METHODS}

\section{Animal Experiments}

Six weeks old female Sprague-Dawley rats (200 g) from Orient Bio (Seongnam, Korea) were cared for in the Association for Assessment and Accreditation of Laboratory Animal Care International system. The animal procedure was approved by the Institutional Animal Care and Use Committee of the Yonsei University College of Medicine.

Fifty Sprague-Dawley rats were divided into 4 groups; normal control $(n=10)$, normal-menthol $(n=10)$, BOO $(n=15)$, BOOmenthol $(n=15)$. BOO was induced by following the methods described in a previous study [2]. Briefly, the rats were anesthetized with a mixture of Zoletil (30 mg/kg; Virbac, Carros cedex, France) and Rompun (10 mg/kg; Bayer Korea Ltd, Seoul, Korea), and the bladder and proximal urethra were exposed through a lower midline abdominal incision. The proximal urethra was carefully freed from the vaginal wall to avoid injury to the periurethral blood vessels. A polyethylene catheter with an inner diameter of $1.40 \mathrm{~mm}$ was inserted into the urethra and the proximal urethra was tied loosely with $3 / 0$ silk, thus enabling the catheter to move freely. After the catheter was removed, the abdominal wound was closed and the rats were given $150 \mathrm{mg} / \mathrm{kg}$ ampicillin intramuscularly once per week for 3 weeks [4].

\section{Tissue Preparation}

After cystometry, bladder tissues were obtained from intraperitoneally anesthetized rats. Bladder weights were recorded before fixation. A portion of each bladder was fixed in $4 \%$ paraformaldehyde for a paraffin block and the rest was stored at $-80^{\circ} \mathrm{C}$ for RT-PCR analysis. Specimens were sectioned at $4 \mu \mathrm{m}$.

\section{Cystometry}

At 3 weeks after surgery, rats were anaesthetized with a mixture of Zoletil and Rompun $(1 \mathrm{~mL} / \mathrm{kg})$, and the bladder was exposed. A PE-50 tube, filled with saline and with the end flared by heat, was inserted into the bladder through the dome and 3/0 silk was released. After the abdominal incision was closed, the rats were placed in a restraining cage, and were allowed to recover from anesthesia for 1 to 2 hours until they awakened. The catheter was connected to a pressure transducer and syringe pump by a three-way stopcock. Cystometry was performed by infusing physiological saline into the bladder of normal and $\mathrm{BOO}$ rats at a slow infusion rate $(0.04 \mathrm{~mL} / \mathrm{min})$. Cystometric variables were measured during saline infusion for 2 hours to evaluate bladder function. After measuring minimum number of stable micturition cycles, the saline was replaced with menthol ( $3 \mathrm{mM}$ in saline) and infused for 1 hour. During infusion, bladder pressure immediately before micturition and the micturition pressure (MP), the intercontraction interval (ICI), and the threshold pressure (TP) were monitored.

\section{Histological Evaluation and Immunofluorescence}

Evaluation of bladder histology was performed by use of Masson's trichrome stain. The distribution of collagen and smooth muscle was assessed by staining with the Trichrome Stain (Masson) kit (Sigma Chemicals, Balcatta, WA, USA) according to the manufacturer's protocol. All stained samples were captured by using an Olympus inverted microscope ( $\times 40$ magnification).

To investigate the expression of TRPM8, tissue sections were deparaffinized in xylene at room temperature for 20 minutes and rehydrated through a decreasing alcohol series up to distilled 
water. The bladders were washed with phosphate-buffered saline (PBS), blocked with 10\% normal horse serum for 15 minutes, and incubated overnight at $4^{\circ} \mathrm{C}$ with TRPM8 antibody (Phoenix Pharmaceuticals, Belmont, CA, USA), diluted 1:100 in SD buffer (1.0 M PBS, 9.5\% thimerosal, $0.01 \%$ saponin, and $1 \%$ normal goat serum). On the following day, slides were rinsed with SD buffer three times and then incubated with Alexa Fluor 488 (Invitrogen, Carlsbad, CA, USA) at room temperature for 1 hour in a dilution of 1:200 in SD buffer. Slides were again washed three times (5 minutes each) with $0.1 \mathrm{M}$ PBS. As negative controls, the primary antibodies were substituted with PBS. TRPM8positive cells were observed under an Olympus fluorescence inverted microscope ( $\times 200$ magnification).

\section{RT-PCR}

Total RNA was isolated with TRIzol reagent (Invitrogen), and gene amplification was performed by using a one-step RT-PCR kit (QIAGEN, Valencia, CA, USA). The reaction conditions followed methods described by Stein et al. [13]. The following primers were used: TRPM8, Forward 5'-CAAGTTTGTCCGCCTCTTCC-3', Reverse 5'-ACCGCCAGCTCCAGACAGTT-3'; glyceraldehyde-3-phosphate dehydrogenase, Forward 5'-CGTGGAGTCTACTGGTGTCTTCACC-3', Reverse 5'-GATGGCATGGACTGTGGTCATGAGC-3'. The PCR products were electrophoresed in a $1 \%$ agarose gel in Tris-borate ethylenediaminetetraacetic acid buffer, and their sizes were checked. Intensity was analyzed by densitometric scanning analysis (TINA ver. 2.10e, Raytest Isotopenme gerate $\mathrm{GmbH}$, Staubenhardt, Germany), and the relative density was expressed as a ratio of the control value.

\section{Statistical Analysis}

Quantitative data are expressed as means \pm standard deviations.

Mann-Whitney $\mathrm{U}$ tests were used to assess differences, and
$\mathrm{P}<0.05$ was considered statistically significant.

\section{RESULTS}

\section{Cystometry}

After the completion of the experiments, 44 animals survived, including 9 in the normal control group, 10 in the normal-menthol group, 14 in the BOO group and 11 in the BOO-menthol group. At 3 weeks after surgery, the bladder weight of the $\mathrm{BOO}$ rats was significantly increased $(126.0 \pm 6.5 \mathrm{mg}, \mathrm{n}=19$ vs. 370.6 $\pm 31.1 \mathrm{mg}, \mathrm{n}=25 ; \mathrm{P}<0.001)$ (Table 1). Cystometry showed that ICI $(428.2 \pm 23.4 \mathrm{sec}$ vs. $880.4 \pm 51.2 \mathrm{sec}, \mathrm{P}<0.001), \mathrm{MP}(25.7 \pm$ $1.01 \mathrm{cmH}_{2} \mathrm{O}$ vs. $\left.71.80 \pm 3.01 \mathrm{cmH}_{2} \mathrm{O}, \mathrm{P}<0.001\right)$, and TP $(2.9 \pm$ $0.25 \mathrm{cmH}_{2} \mathrm{O}$ vs. $9.2 \pm 1.58 \mathrm{cmH}_{2} \mathrm{O}, \mathrm{P}<0.01$ ) were significantly higher in $\mathrm{BOO}$ rats than in normal rats (Table 1, Fig. 1). In addition, the data showed persistent $\mathrm{DO}$, which is a known sign of $\mathrm{OAB}$, in the $\mathrm{BOO}$ group but not in the normal control group (Fig. 1). In the normal-menthol group, ICI $(428.2 \pm 23.4 \mathrm{~cm}$ $\mathrm{H}_{2} \mathrm{O}$ vs. $\left.312.6 \pm 18.1 \mathrm{cmH}_{2} \mathrm{O}, \mathrm{P}<0.01\right)$ and TP $(2.9 \pm 0.25 \mathrm{~cm}-$ $\mathrm{H}_{2} \mathrm{O}$ vs. $2.6 \pm 0.3 \mathrm{cmH}_{2} \mathrm{O}$ ) were lower than compared with normal rats, and $\mathrm{MP}\left(25.7 \pm 1.01 \mathrm{cmH}_{2} \mathrm{O}\right.$ vs. $30.0 \pm 1.3 \mathrm{cmH}_{2} \mathrm{O}$, $\mathrm{P}<0.05$ ) was higher (Table 1, Fig. 1). In the BOO-menthol group, ICI $(880.4 \pm 51.2 \mathrm{sec}$ vs. $646.5 \pm 71.9 \mathrm{sec}, \mathrm{P}<0.05)$ was lower, and $\mathrm{MP}\left(71.8 \pm 3.01 \mathrm{cmH}_{2} \mathrm{O}\right.$ vs. $80.0 \pm 3.0 \mathrm{cmH}_{2} \mathrm{O}, \mathrm{P}<$ $0.05)$ and $\mathrm{TP}\left(9.2 \pm 1.5 \mathrm{cmH}_{2} \mathrm{O}\right.$ vs. $\left.11.1 \pm 2.3 \mathrm{cmH}_{2} \mathrm{O}\right)$ were higher than in the BOO group (Table 1, Fig. 1).

\section{Collagen and Smooth Muscle Components and Localization of TRPM8}

The difference in collagen and smooth muscle components was investigated between normal and BOO bladders. A 2- or 3-fold increase in bladder wall thickness was observed in BOO bladder compared with normal bladder. Furthermore, detrusor muscle hypertrophy and a thick mucosa layer were observed in $\mathrm{BOO}$

Table 1. Bladder weight and cystometric parameters in each group

\begin{tabular}{lcccc}
\hline & Normal & Normal $(\mathrm{M})$ & BOO & BOO (M) \\
\hline Bladder weight $(\mathrm{mg})$ & & $126.0 \pm 6.5$ & & $370.6 \pm 31.1^{\mathrm{b}), \mathrm{f})}$ \\
Cystometric parameters & & & & \\
$\mathrm{ICI}(\mathrm{sec})$ & $428.2 \pm 23.4$ & $312.6 \pm 18.1^{\mathrm{a}), \mathrm{d})}$ & $880.4 \pm 51.2^{\mathrm{b}), \mathrm{f})}$ & $646.5 \pm 71.9^{\mathrm{c}), \mathrm{h})}$ \\
$\mathrm{MP}\left(\mathrm{cmH}_{2} \mathrm{O}\right)$ & $25.7 \pm 1.01$ & $30.0 \pm 1.3^{\mathrm{a}), \mathrm{e})}$ & $71.8 \pm 3.01^{\mathrm{b}), \mathrm{f})}$ & $80.0 \pm 3.0^{\mathrm{c}, \mathrm{h})}$ \\
$\mathrm{TP}\left(\mathrm{cmH}_{2} \mathrm{O}\right)$ & $2.9 \pm 0.25$ & $2.6 \pm 0.3$ & $9.2 \pm 1.58^{\mathrm{b}), \mathrm{g})}$ & $11.1 \pm 2.3$ \\
\hline
\end{tabular}

Values are presented as mean $\pm \mathrm{SD}$.

BOO, bladder outlet obstruction; Normal (M), normal-menthol; BOO (M), BOO-menthol.

${ }^{\mathrm{a})}$ Normal vs. Normal (M). ${ }^{\mathrm{b}}$ Normal vs. BOO. ${ }^{\mathrm{c}} \mathrm{BOO}$ vs. $\mathrm{BOO}(\mathrm{M}) .{ }^{\mathrm{d})} \mathrm{P}<0.01 .{ }^{\mathrm{e}} \mathrm{P}<0.05 .{ }^{\mathrm{f})} \mathrm{P}<0.001 .{ }^{\mathrm{g}} \mathrm{P}<0.01 .{ }^{\mathrm{h}} \mathrm{P}<0.05$. 


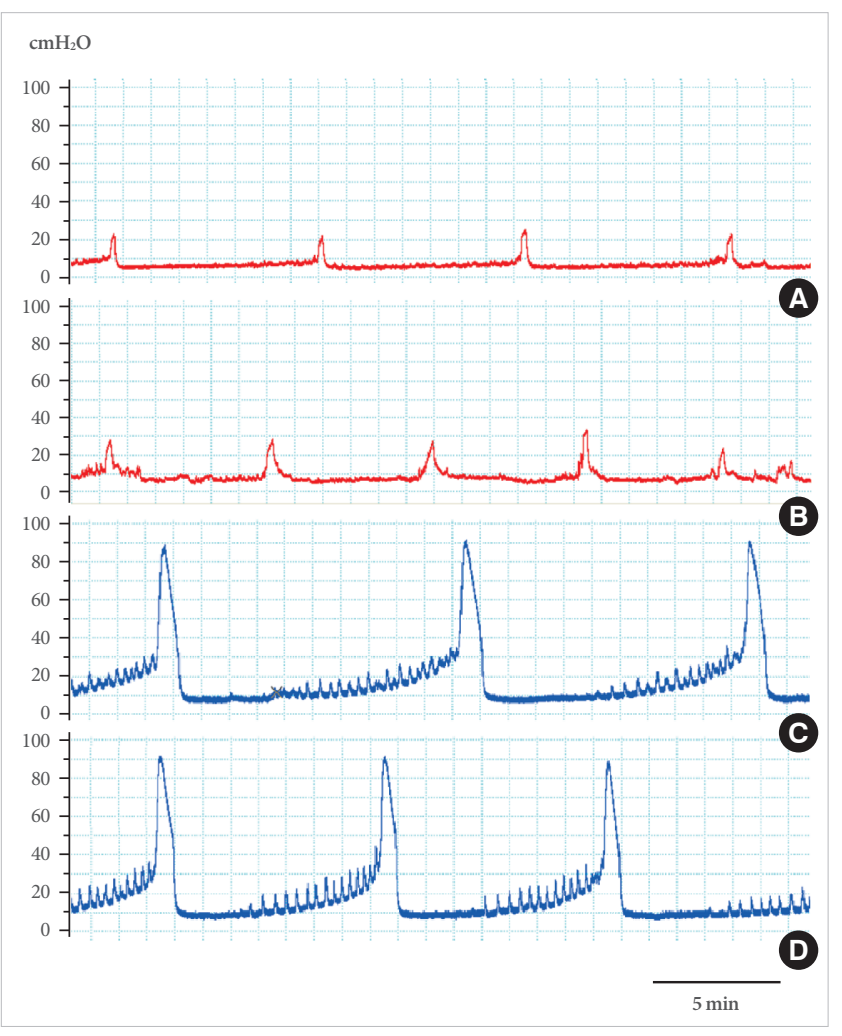

Fig. 1. Cystometry in rats. At 3 weeks after surgery, cystometry was recorded in normal (A), normal-menthol (B), bladder outlet obstruction $(\mathrm{BOO})(\mathrm{C})$ and $\mathrm{BOO}-$ menthol $(\mathrm{D})$ rats. Room temperature saline was infused at $0.04 \mathrm{~mL}$ per minute in all groups. In normal-menthol (B) and BOO-menthol (D) groups, saline was replaced with menthol ( $3 \mathrm{mM}$ in saline, $0.04 \mathrm{~mL} / \mathrm{min}$ ) for 1 hour. Intercontraction interval (ICI), micturition pressure (MP) and threshold pressure were higher in the BOO group (C) than in the normal group (A). After intravesical infusion of menthol, ICIs were decreased and MPs were increased in the treated groups $(B, D)$ compared with the untreated groups $(A, C)$.

bladder. The proportion of collagen was significantly higher in the muscle layer and below the mucosa layer in the BOO bladder compared with the normal group (Fig. 2).

Immunofluorescence showed localization of TRPM8 (green) in the bladder. Expression of TRPM8-positive cells was predominantly in the bladder epithelium but not in the smooth muscle layer. The expression of TRPM8-positive cells was significantly higher in the normal-menthol, BOO, and BOO-menthol groups than in the normal group (Fig. 3).

\section{Gene Expression of TRPM8}

The gene expression of TRPM8 in the bladder was analyzed by RT-PCR and was quantified in each group. The expression of
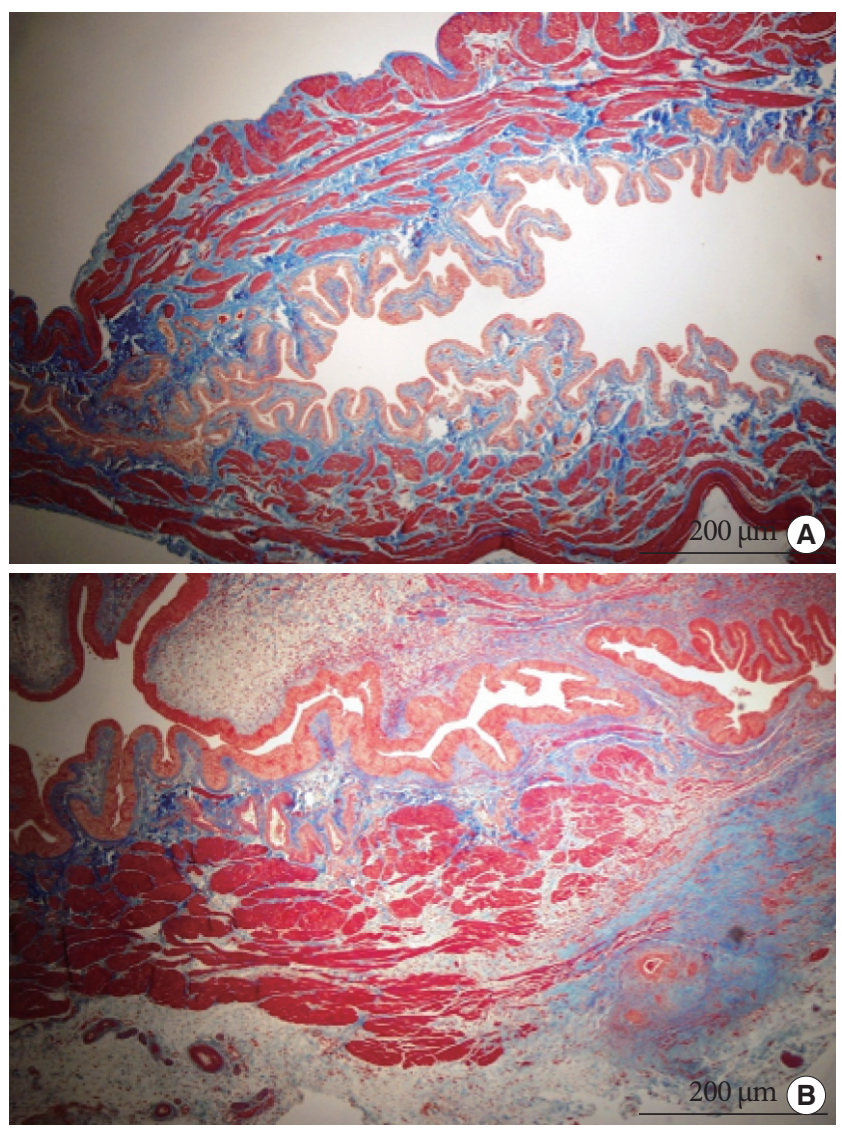

Fig. 2. Collagen and smooth muscle components in normal and bladder outlet obstruction (BOO) bladders. Collagen and smooth muscle were stained by Masson's trichrome in normal (A) and BOO (B) bladder. Bladder tissues show extracellular matrix, collagen, and other connective tissue elements in blue and smooth muscle in red. Magnification reduced from $\times 40$.

TRPM8 mRNA was detected in the bladder, and a relatively low level of TRPM8 was observed in normal bladder. On the other hand, the expression of TRPM8 in BOO was significantly higher than in normal bladder. After menthol treatment, the intensity of TRPM8 expression was increased in both the normal-menthol and BOO-menthol groups (Fig. 4).

\section{DISCUSSION}

The results of the present study show the expression of TRPM8 before and after menthol treatment in normal and $\mathrm{BOO}$ rats. Voiding dysfunction and $\mathrm{OAB}$ symptoms are commonly caused by $\mathrm{BOO}$. $\mathrm{BOO}$ studies have reported physiological and pathological changes through the use of cystometry or immunohistochemistry. McMurray et al. [24] showed that empty bladder 

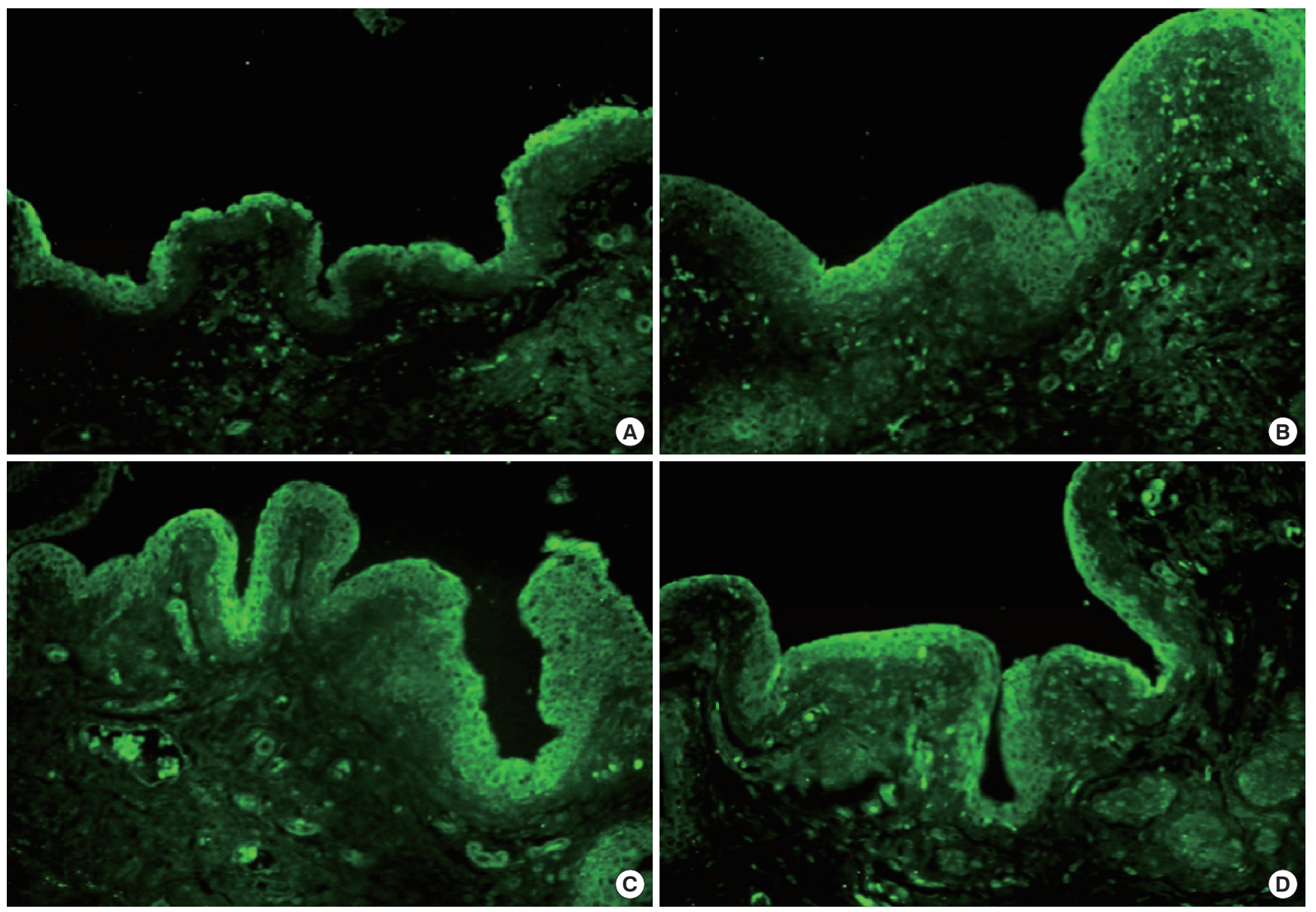

Fig. 3. Expression and localization of transient receptor potential cation channel subfamily M member 8 (TRPM8) in bladder by fluorescence microscopy. TRPM8-positive cells appeared green in the normal (A), normal-menthol (B), bladder outlet obstruction (BOO) (C), and BOO-menthol (D) groups. TRPM8-positive cells were expressed in the bladder epithelium. TRPM8 expression was increased in the normal-menthol (B), BOO (C), and BOO-menthol (D) groups compared with the normal group (A). Magnification reduced from $\times 200$.

pressure in normal urethane-anesthetized guinea pig bladder slowly rises as saline is infused and then the full bladder eliminates the saline. Those authors also suggested that the major cystometry data were bladder capacity, TP, MP, and residual volume. Previous studies have shown that the bladder weight was significantly higher in BOO bladder than in normal bladder $[2,8]$. In our study, cystometry was performed by infusing physiological saline into the bladder at a slow infusion rate $(0.04$ $\mathrm{mL} / \mathrm{min}$ ) for collection of control recordings in normal and $\mathrm{BOO}$ rats and was recorded again at 3 weeks after surgery. All parameters (bladder weight; ICI, $\mathrm{P}<0.001$; $\mathrm{MP}, \mathrm{P}<0.01$; and $\mathrm{TP}, \mathrm{P}<0.05)$ were significantly increased and $\mathrm{DO}$ was observed in the $\mathrm{BOO}$ group (Table 1, Fig. 1). The results are typical patterns of $\mathrm{BOO}$ and are similar to the results of previous studies [4].
In a prior study, histopathological analysis of mice with BOO showed smooth muscle hypertrophy of the detrusor on hematoxylin and eosin staining, and increased collagen deposition between muscle fascicles on Masson's trichrome staining compared with controls [25]. Our Masson's trichrome staining results of $\mathrm{BOO}$ and control bladders were similar to the results of previous research. A 2- or 3-fold increase in bladder wall thickness was observed in BOO bladder compared to with normal bladder. Furthermore, detrusor muscle hypertrophy and a thick mucosa layer were observed in $\mathrm{BOO}$ bladder. The proportion of collagen was relatively higher in the muscle layer and below the mucosa layer in the BOO bladder compared with the normal group (Fig. 2). Therefore, increased bladder wall thickness and proportion of collagen probably affect bladder contraction and voiding dysfunction. 

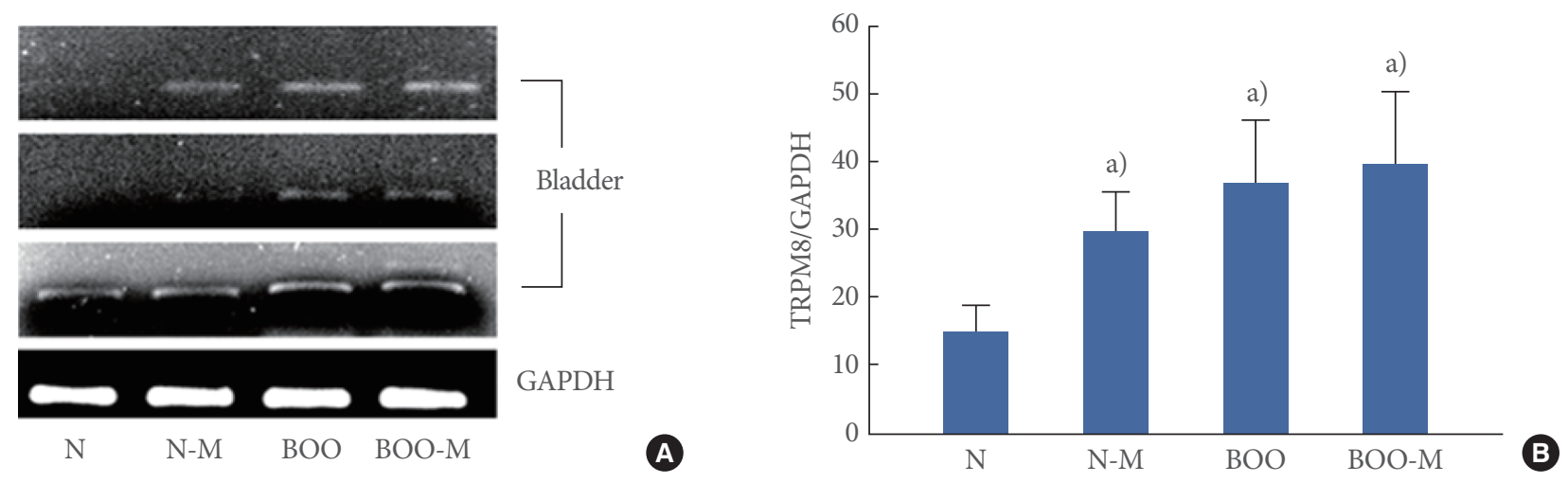

Fig. 4. Gene expression of transient receptor potential cation channel subfamily M member 8 (TRPM8) in bladder. The gene expression of TRPM8 in bladder was analyzed by reverse transcription-polymerase chain reaction (A) and quantified (B) in the normal (N), normal-methol (N-M), bladder outlet obstruction (BOO), and BOO-menthol (BOO-M) groups. Gene expression was increased in the normal-menthol, $\mathrm{BOO}$ and $\mathrm{BOO}$-menthol groups compared with the normal group ( $\mathrm{n}=3$ for each group). GAPDH, glyceraldehyde-3-phosphate dehydrogenase. ${ }^{\text {a) }} \mathrm{P}<0.05$ when compared to normal group.

Andersson et al. [10] noted the role of the TRP family to in the mechanism of $\mathrm{DO} / \mathrm{OAB}$ and suggested that this could be a new therapeutic opportunity for DO/OAB. Prior investigators have reported that TRPM8 is a non selective cation channel, known as the cold menthol receptor-1 $[7,10,19,20]$. TRPM8 is an innocuous cold receptor that is activated by moderate cooling $\left(<25^{\circ} \mathrm{C}\right)[12]$. The cooling sensation is mediated by unmyelinated $\mathrm{C}$-fibers and myelinated $\mathrm{A} \delta$ primary afferent fibers [26]. The expression of TRPM8 was identified in skeletal and smooth muscle, epithelium of the prostate, lung, bladder and urogenital tract $[13,19,27]$. Moreover, the proportion of TRPM8 expression is very low in normal condition [27]. Stein et al. [13] demonstrated the presence of TRPM8 in the bladder and DRG through immunofluorescence and RT-PCR [14,15]. Du et al. [7] reported that TRPM8 was detected in bladder mucosa but not in the muscle of either normal or BOO human bladder $[12,13]$. Mukerji et al. [19] noted that the expression of TRPM8 increases in $\mathrm{OAB}$ animal models and the relative density correlates with urinary frequency, but not urgency [19]. We investigated the expression of TRPM8 to evaluate the difference between normal and $\mathrm{BOO}$ groups. In the immunofluorescence and RTPCR experiments, the expression of TRPM8 was observed in bladder epithelium, and was increased in $\mathrm{BOO}$ compared with the normal group (Figs. 3, 4). TRPM8 in the bladder was mainly located in the epithelium although some TRPM8-positive cells were detected beneath the epithelium (Fig. 3). The expression of TRPM8 mRNA was detected in the bladder, and relatively low level of TRPM8 was observed in normal bladder. On the other hand, the expression of TRPM8 in BOO was signifi- cantly higher than in normal bladder (Fig. 4).

To reveal the role of TRPM8 in BOO bladder, we investigated the variations in TRPM8 expression with menthol treatment in both the normal and the $\mathrm{BOO}$ groups. Detrusor contraction by the bladder cooling reflex is mediated by $\mathrm{C}$-fiber afferents and TRPM8 in BOO $[7,13,14]$. Nomoto et al. [16] reported that voided volume, volume threshold, and pressure threshold for inducing micturition were reduced in normal rat bladder treated with $3 \mathrm{mM}$ menthol. However, the role of TRP channels in the bladder and DRG in the BOO rat model is unclear. Menthol, which is a TRPM8 agonist, was given to the normal and BOO groups to investigate the function of TRPM8. In our cystometry results, ICI was significantly decreased and MP was increased in both the normal and the BOO groups after menthol infusion. TRPM8-positive cells were more abundant in the bladder epithelium of the normal-menthol and BOO-menthol groups. However, OAB symptoms were not observed on cystometry, although the expression of TRPM8 increased in the normal-menthol group (Table 1, Fig. 1). Hayashi et al. [21] reported that the MP after menthol treatment was increased by reinforcing the contraction of detrusor muscle or increasing the urethral outlet resistance during the micturition phase. Therefore, menthol probably contributes to the voiding by bladder contraction.

In previous studies, Du et al. [7] reported that TRPM8 was abundant in the epithelium of human urinary bladder compared with bladder muscle, and that TRPM8 mRNA was not affected in BOO compared with normal bladder mucosa. Sun et al. [28] reported that the density of TRPM8-immuoreactive nerve fibers 
is associated with $\mathrm{OAB}$ and pain symptoms [15,19]. In our immunofluorescence results, TRPM8-positive cells were more abundant in the bladder epithelium of the normal-menthol, $\mathrm{BOO}$, and $\mathrm{BOO}-$ menthol groups than in the normal group (Fig. 3). The expression of TRPM8 mRNA was observed in the BOO and menthol treatment groups (Fig. 4). However, OAB symptoms were only observed in the $\mathrm{BOO}$ and $\mathrm{BOO}-m e n t h o l$ groups. Therefore, OAB symptoms are not probably caused by the expression of TRPM8 and menthol treatment, although TRPM8 would affect detrusor contraction. According to recent reports, the expression of TRPM8 contributes to increasing the intracellular $\mathrm{Ca}^{2+}$ concentration [29]. The increases in $\mathrm{Ca}^{2+}$ concentration accelerate smooth muscle contractility [30]. Therefore, the increase of TRPM8 in BOO may induce entry of $\mathrm{Ca}^{2+}$ from the extracellular space or stores so that the increase of $\mathrm{Ca}^{2+}$ probably causes contraction of smooth muscle in BOO. Despite substantial research efforts, however, the role and mechanism of TRPM8 remain controversial. OAB in BOO models may be caused by complex pathways. Although the effect of TRPM8 in $\mathrm{BOO}$ requires further investigation, these data indicate that the increased TRPM8 expression in the bladder with $\mathrm{BOO}$ is associated with the micturition reflex. TRPM8 expression is likely significant to understanding voiding dysfunction in $\mathrm{BOO}$.

\section{CONFLICT OF INTEREST}

No potential conflict of interest relevant to this article was reported.

\section{ACKNOWLEDGEMENTS}

This study was supported by a faculty research grant of Yonsei University College of Medicine for 2007 (6-2007-0113).

\section{REFERENCES}

1. Kita M, Yunoki T, Takimoto K, Miyazato M, Kita K, de Groat WC, et al. Effects of bladder outlet obstruction on properties of $\mathrm{Ca} 2+-$ activated $\mathrm{K}+$ channels in rat bladder. Am J Physiol Regul Integr Comp Physiol 2010;298:R1310-9.

2. Tanaka H, Kakizaki H, Shibata T, Mitsui T, Koyanagi T. Effect of preemptive treatment of capsaicin or resiniferatoxin on the development of pre-micturition contractions after partial urethral obstruction in the rat. J Urol 2003;170:1022-6.

3. Steers WD, De Groat WC. Effect of bladder outlet obstruction on micturition reflex pathways in the rat. J Urol 1988;140:864-71.

4. Lee SR, Hong CH, Choi YD, Kim JH. Increased urinary nerve growth factor as a predictor of persistent detrusor overactivity after bladder outlet obstruction relief in a rat model. J Urol 2010;183: 2440-4.

5. Kim JC, Yoo JS, Park EY, Hong SH, Seo SI, Hwang TK. Muscarinic and purinergic receptor expression in the urothelium of rats with detrusor overactivity induced by bladder outlet obstruction. BJU Int 2008;101:371-5.

6. Li L, Jiang C, Song B, Yan J, Pan J. Altered expression of calciumactivated $\mathrm{K}$ and $\mathrm{Cl}$ channels in detrusor overactivity of rats with partial bladder outlet obstruction. BJU Int 2008;101:1588-94.

7. Du S, Araki I, Kobayashi H, Zakoji H, Sawada N, Takeda M. Differential expression profile of cold (TRPA1) and cool (TRPM8) receptors in human urogenital organs. Urology 2008;72:450-5.

8. Pandita RK, Fujiwara M, Alm P, Andersson KE. Cystometric evaluation of bladder function in non-anesthetized mice with and without bladder outlet obstruction. J Urol 2000;164:1385-9.

9. Yuan X, Wu S, Lin T, He D, Li X, Liu S, et al. Role of nitric oxide synthase in bladder pathologic remodeling and dysfunction resulting from partial outlet obstruction. Urology 2011;77:1008.e1-8.

10. Andersson KE, Gratzke C, Hedlund P. The role of the transient receptor potential (TRP) superfamily of cation-selective channels in the management of the overactive bladder. BJU Int 2010;106:111427.

11. Everaerts W, Gevaert T, Nilius B, De Ridder D. On the origin of bladder sensing: $\operatorname{Tr}(\mathrm{i})$ ps in urology. Neurourol Urodyn 2008;27: 264-73.

12. Skryma R, Prevarskaya N, Gkika D, Shuba Y. From urgency to frequency: facts and controversies of TRPs in the lower urinary tract. Nat Rev Urol 2011;8:617-30.

13. Stein RJ, Santos S, Nagatomi J, Hayashi Y, Minnery BS, Xavier M, et al. Cool (TRPM8) and hot (TRPV1) receptors in the bladder and male genital tract. J Urol 2004;172:1175-8.

14. Tsukimi Y, Mizuyachi K, Yamasaki T, Niki T, Hayashi F. Cold response of the bladder in guinea pig: involvement of transient receptor potential channel, TRPM8. Urology 2005;65:406-10.

15. Hayashi T, Kondo T, Ishimatsu M, Yamada S, Nakamura K, Matsuoka K, et al. Expression of the TRPM8-immunoreactivity in dorsal root ganglion neurons innervating the rat urinary bladder. Neurosci Res 2009;65:245-51.

16. Nomoto Y, Yoshida A, Ikeda S, Kamikawa Y, Harada K, Ohwatashi A, et al. Effect of menthol on detrusor smooth-muscle contraction and the micturition reflex in rats. Urology 2008;72:701-5.

17. Bidaux G, Roudbaraki M, Merle C, Crepin A, Delcourt P, Slomian- 
ny C, et al. Evidence for specific TRPM8 expression in human prostate secretory epithelial cells: functional androgen receptor requirement. Endocr Relat Cancer 2005;12:367-82.

18. Kochukov MY, McNearney TA, Fu Y, Westlund KN. Thermosensitive TRP ion channels mediate cytosolic calcium response in human synoviocytes. Am J Physiol Cell Physiol 2006;291:C424-32.

19. Mukerji G, Yiangou Y, Corcoran SL, Selmer IS, Smith GD, Benham $\mathrm{CD}$, et al. Cool and menthol receptor TRPM8 in human urinary bladder disorders and clinical correlations. BMC Urol 2006;6:6.

20. Everaerts W, Vriens J, Owsianik G, Appendino G, Voets T, De Ridder $\mathrm{D}$, et al. Functional characterization of transient receptor potential channels in mouse urothelial cells. Am J Physiol Renal Physiol 2010;298:F692-701.

21. Hayashi T, Kondo T, Ishimatsu M, Takeya M, Igata S, Nakamura K, et al. Function and expression pattern of TRPM8 in bladder afferent neurons associated with bladder outlet obstruction in rats. $\mathrm{Au}$ ton Neurosci 2011;164:27-33.

22. Peier AM, Moqrich A, Hergarden AC, Reeve AJ, Andersson DA, Story GM, et al. A TRP channel that senses cold stimuli and menthol. Cell 2002;108:705-15.

23. Mergler S, Strowski MZ, Kaiser S, Plath T, Giesecke Y, Neumann M, et al. Transient receptor potential channel TRPM8 agonists stimulate calcium influx and neurotensin secretion in neuroendo- crine tumor cells. Neuroendocrinology 2007;85:81-92.

24. McMurray G, Casey JH, Naylor AM. Animal models in urological disease and sexual dysfunction. Br J Pharmacol 2006;147 Suppl 2: S62-79.

25. Dhar K, Dhar G, Majumder M, Haque I, Mehta S, Van Veldhuizen PJ, et al. Tumor cell-derived PDGF-B potentiates mouse mesenchymal stem cells-pericytes transition and recruitment through an interaction with NRP-1. Mol Cancer 2010;9:209.

26. McKemy DD, Neuhausser WM, Julius D. Identification of a cold receptor reveals a general role for TRP channels in thermosensation. Nature 2002;416:52-8.

27. Yudin Y, Rohacs T. Regulation of TRPM8 channel activity. Mol Cell Endocrinol 2012;353:68-74.

28. Sun B, Li Q, Dong L, Rong W. Ion channel and receptor mechanisms of bladder afferent nerve sensitivity. Auton Neurosci 2010;153:26-32.

29. Bidaux G, Beck B, Zholos A, Gordienko D, Lemonnier L, Flourakis $\mathrm{M}$, et al. Regulation of activity of transient receptor potential melastatin 8 (TRPM8) channel by its short isoforms. J Biol Chem 2012; 287:2948-62.

30. Hill-Eubanks DC, Werner ME, Heppner TJ, Nelson MT. Calcium signaling in smooth muscle. Cold Spring Harb Perspect Biol 2011; 3:a004549. 